\title{
Telorragia en una lactante menor
}

\author{
Telorrhagia in a young infant \\ Themis Gwendolyne Aguilar-Arciga* \\ * Hospital Memorial de Morelia, Michoacán.
}

\begin{abstract}
RESUMEN
Se presenta el caso de una lactante de nueve meses con telorragia, lo cual es un síntoma poco frecuente. Después de la revisión clínica, así como de análisis de exámenes de laboratorio y de USG mamario, se llegó a la conclusión que se trataba de ectasia ductal mamaria, la cual es una condición benigna y auto-limitada.
\end{abstract}

Palabras clave: Telorragia, ectasia ductal mamaria, lactante.

\section{ABSTRACT}

We present the case of a nine-month-old female infant with telorrhagia, which is a rare symptom. After the clinical review, as well as analysis of laboratory tests and breast ultrasound, it was concluded that the telorrhagia was due to breast ductal ectasia, which is a benign and self-limited condition.

Keywords: Telorrhagia, breast ductal ectasia, infant.

\section{INTRODUCCIÓN}

La secreción sanguínea a través del pezón se denomina telorragia, la cual es un síntoma muy poco frecuente, pero que puede generar alarma en los padres y equipo de salud. ${ }^{1}$

En niños, su principal causa es la ectasia ductal mamaria (EDM), la cual es una alteración benigna del tejido mamario que se caracteriza por dilatación del conducto mamario, fibrosis e inflamación periductal. ${ }^{2}$ En promedio, la EDM se presenta a los cuatro años de edad, pero los casos reportado tienen una variación de dos meses de edad hasta los 13 años. Además, es más frecuente en varones, en una proporción de 5:2.

\section{PRESENTACIÓN DEL CASO}

Lactante de sexo femenino de nueve meses de edad, producto de la primera gesta, sin antecedentes per- sonales patológicos importantes, con alimentación al seno materno, inicio de ablactación a los seis meses. Su crecimiento y desarrollo neurológico eran normales.

La madre la lleva a consulta porque ha observado salida de secreción sanguínea unilateral del pezón izquierdo, que manchaba la ropa. La madre negó traumatismo mamario.

A la exploración física del tórax no se detectó alguna tumoración o dolor a la palpación; a la compresión gentil de la glándula mamaria se corrobora salida de secreción sanguinolenta (Figura 1). El resto de la exploración fue normal.

Los resultados de biometría hemática y niveles de hormonas fueron normales. La ecografía mamaria también fue normal. Por lo anterior, se concluyó que se trataba de ECM, por lo que se manejó conservadoramente con vendaje compresivo mamario suave. Se

Correspondencia: Themis Gwendolyne Aguilar-Arciga, E-mail: gwendolyne.ga@gmail.com

Citar como: Aguilar-Arciga TG. Telorragia en una lactante menor. Rev Mex Pediatr. 2021; 88(4): 169-170. https://dx.doi.org/10.35366/102784 


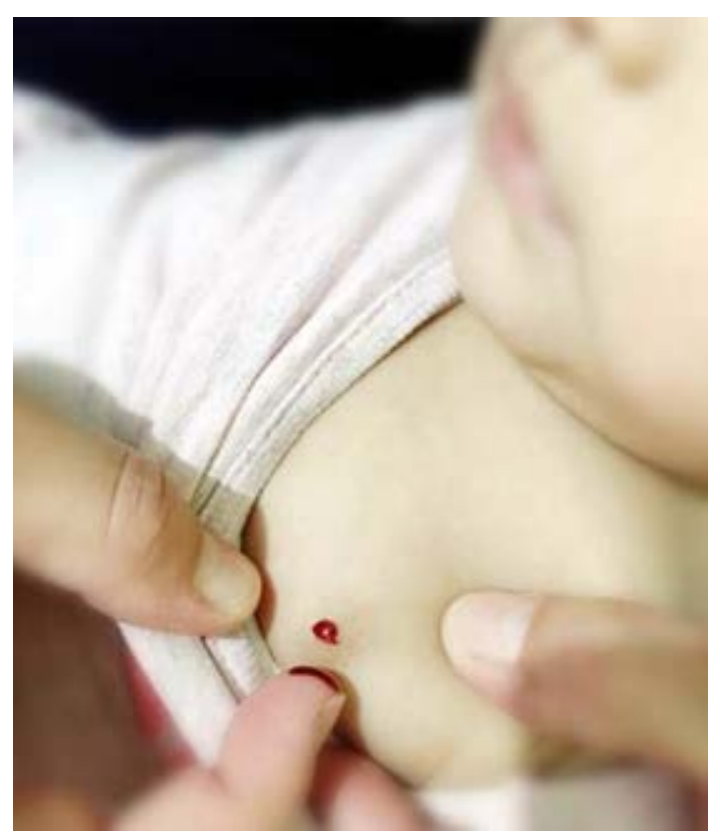

Figura 1: Glándula mamaria izquierda que, a la compresión gentil, presenta secreción sanguinolenta por el pezón.

realizó seguimiento a las cuatro, 24 y 48 semanas, remitiendo el sangrado desde la primera cita.

\section{COMENTARIO}

La EDM es una condición benigna que se manifiesta como secreción sanguínea unilateral o bilateral que puede o no asociarse a aumento de volumen mamario. La evolución natural es a la desaparición del sangrado, sin tratamiento.

Se desconoce la etiología, aunque se ha aceptado que es causada por estímulos hormonales, anomalías estructurales del tejido mamario, infecciones o por hematopoyesis extramedular..$^{2.3}$

A fin de descartar otras patologías, se puede solicitar ecografía mamaria, determinación de niveles hormonales de prolactina, estradiol y hormonas tiroideas. ${ }^{3}$

\section{REFERENCIAS}

1. Ascaso Matamala AM, Amiguet Biain M, Morales Ferruz R, Sobrevia Elfau MT et al. Ectasia ductal mamaria, una entidad poco frecuente en la edad pediátrica. A propósito de un caso. Arch Argent Pediatr. 2018; 116(6): e782-e784.

2. Zegpi MS, Downey C, Vial-Letelier V. Ectasia ductal mamaria en niños, a propósito de un caso clínico. Rev Chil Pediatr. 2015; 86(4): 287-229. doi: 10.1016/j.rchipe.2015.07.012.

3. Affranchino PN, Oglietti JP, Amoedo D, Nastri M. Telorragia en el lactante por ectasia ductal. Consideraciones acerca de dos casos. Arch Argent Pediatr. 2013; 111: e152-e155. 